\title{
Ecopoéticas na literatura brasileira: memória e modernidade na poesia de Joaquim Cardozo
}

Zélia M. Bora ${ }^{1}$

Resumo: A ligação intrínseca entre a literatura e a sociedade pressupõe que ela não só represente a sociedade, em suas mais diversas manifestações, como também proponha reflexões sobre o corpo social e sua relação com seus sujeitos. Uma das questões contemporâneas que vêm influenciando a produção crítico-literária em vários continentes é a conexão entre o sujeito e o meio ambiente. Embora a representação da natureza não seja um tema inovador na literatura, as formas de interpelação crítica, através de métodos como a ecocrítica, emergem como um instrumento que pode prover para o texto literário novas formas de entender a interação entre o ser humano e o meio ambiente. Pensar na natureza, em nossos dias, resulta em implicações profundas de caráter global, especialmente quando o destino do Planeta e de todos os seres vivos está em crise. Pensar na literatura brasileira levando-se em consideração ferramentas como a ecocrítica requer um delicado exercício metodológico que estabeleça os limites textuais apresentados pelo texto literário e a acomodação do tema 'ecologia' sugerido por este texto. Nesse caso, a noção de crise poderá ser explícita ou não e ser mais evidente em alguns autores do que em outros. Resta-nos, então, ler os textos de forma coerente, a partir de uma atualização entre a leitura proposta e os limites de composição textual. Assim, tendo em vista esses pressupostos, propomo-nos a fazer uma leitura do poeta modernista Joaquim Cardozo, com o fim de entender sua visão sobre o meio ambiente e o papel da natureza, especialmente, no poema "Recordações de Tramataia".

Palavras-chave: Ecopoética; Ecocrítica; Memória e Modernidade.

O termo memória é definido como um processo seletivo de fatos passados, lembrados pelos indivíduos. Diversos estudos nos campos da Sociologia, da Cultura, da História, da Neurociência e da Literatura discutiram, sob essas perspectivas, a respeito das implicações do 
termo memória e sua relação com o sujeito, tanto o individual quanto o coletivo. Quando transpomos o termo para a poesia, ele adquire certas especificidades. Embora saibamos que, como um ente social, o poeta encontra-se veiculado à construção de uma memória sociocultural, a memória poética é considerada como um processo estético de representação de certo passado e, como um processo seletivo, lança mão de recursos poéticos para atribuir significado à experiência ou à lembrança de forma persuasiva, por meio de um controle rigoroso dos elementos que compõem a linguagem. Entendo que a utilização desses recursos dá à criação poética um estado simbólico de "animação suspensa", em que a sociedade passa a ser tratada de acordo com os parâmetros subjetivos (GOSMANN, 2008, p.14) ${ }^{1}$.

Para Gosmann,

poetic memory, in contrast, posits that the self is more than the compound of the accuracy, linearity, casuality or coherence or historic memory, and it reaches beyond the accountable facts of a life toward the notion of the self that is dynamic expansive, and full of potential (GOSMANN, 2008,p.1)

A memória poética, em contraste, pressupõe que o Eu é mais do que um compósito de certeza, linearidade, casualidade, coerência ou memória histórica e tem alcance para além dos fatos críveis de uma vida de forma dinâmica, expansiva e cheio de potencialidades (GOSMANN, 2008,1).

No Ocidente, a relação entre a memória e o ato de narrar foi definida por Plotino e Plutarco, que correlacionaram a identidade pessoal à escrita da vida. Com esses dois elementos, surgiu a ideia da criação poética (GOSMANN, 2008, p.3) Posteriormente, essas especulações de caráter filosófico influenciaram as concepções estéticas sobre a natureza da escrita poética e o papel do Eu poético. Definida a relação entre a memória e o ato de narrar, na pós-modernidade, o Eu será identificado ou interpelado de acordo com o lugar da enunciação. Assim, será possível observar se ele ainda será o mesmo que narra sua experiência. Esse processo também é extensivo ao narrador prosaico. Nesse contexto, esses

1 Professora Titular da UFPB. Professora Colaboradora do Programa de Pós-Graduação em Letras e Presidente da ASLE Brasil (Association for the Study of Literature and Ecocriticism Brasil). email: zeliambora@gmail.com

Gláuks: Revista de Letras e Artes - jul./ dez. 2019 - Vol 19, $N^{o} 2$, ISSN 2318-7131 
elementos constituem a memória poética. De acordo com Gosmann, "Poetic Memory does not rest on the existence of coherent historic narratives liberated from such standards expresses and constitutes the subjective in different ways" (p.14)

Entretanto, apesar de a memória poética não rejeitar a memória histórica, não tem nenhuma intenção de prover visão crítica historiográfica. Sua narrativa só se preocupa com o passado (GOSMANN, 2008, p.3). Esse elemento específico de definição sobre a memória poética é sobremaneira importante para esta discussão, para que possamos compreender a ecologia poética de Joaquim Cardozo.

\section{Memória poética e a Ecocrítica: uma breve abordagem crítico-teórica}

As literaturas da língua portuguesa, da espanhola e, especialmente, a brasileira não podem deixar de discutir sobre as mudanças de paradigmas crítico-teóricos propostos pela mais recente abordagem teórica - a Ecocrítica (Ecocriticism). O termo Ecocrítica foi empregado, pela primeira vez, por Wiliam Rueckarth (1978). O começo das especulações crítico-teóricas sobre o assunto foi comumente marcado para os anos oitenta. Porém, em seu livro, A Century of Early Ecocriticism (2001), David Mazel cita publicações sobre o assunto na literatura anglo-americana, entre 1864 e 1964 (SLOVIC, 2004, pp. 4-5). Como um paradigma cultural e acadêmico, a relação entre a literatura e o meio ambiente e suas primeiras conceitualizações teóricas foram determinadas por trabalhos seminais da crítica literária anglo-saxã por meio de livros como Environmental Imagination e Ecocriticism Reader, ambos de 1996. Entretanto uma nova "onda" de trabalhos crítico-teóricos se estendeu nesse novo milênio, marcado significativamente pela obra de Laurence Buel, The Future of Ecocriticism (2005). Esses livros lançaram os pressupostos gerais para a leitura das chamadas literaturas do meio ambiente. Seguiram-se a essas obras várias e rápidas respostas teóricocríticas em forma de inúmeros trabalhos sobre obras canônicas das literaturas inglesa, norteamericana e, posteriormente, outras em língua inglesa, fora dos eixos Europa e América do 
Norte. Desse modo, iniciaram-se estudos sobre autores cujas motivações essenciais de seus trabalhos foram expressas por suas preocupações, tendo o meio ambiente como tema central. A crítica norte-americana produziu significantes leituras das obras de Rachel Carson (19071964) e dos transcendentalistas, como Ralph Waldo Emerson (1803-1882) e Henry David Throreau (1817-1862). Esses trabalhos se tornaram importantes modelos de Literaturas Verdes (Green Studies) e Ecopoética (Ecopoetics) e Literatura Ambiental (Environmental Literature), outras designações para o termo Ecocrítica. Ainda nessa primeira fase, a crítica britânica explorou os trabalhos sobre os românticos ingleses. Foi por meio deles que novas considerações literárias foram elaboradas para compreender a relação entre a literatura e o meio ambiente.

A necessidade de discutir sobre a literatura brasileira e outras literaturas em língua portuguesa e espanhola nos levou a investigar esse parâmetro teórico em relação à literatura brasileira. Tal perspectiva se justifica pelo fato de todas elas terem em comum a mesma raiz o romantismo europeu. Resta, portanto, às literaturas definirem os padrões historiográficos específicos que cada uma assumirá na perspectiva ecocrítica. Assim, cada historiografia literária poderá sugerir os próprios caminhos para compreender sua trajetória ecológica literária ${ }^{2}$.

O estudo das literaturas do meio ambiente inicia-se por meio do estudo do romantismo europeu. Como um termo crítico-teórico, a Ecocrítica inglesa é bastante relevante. O romantismo inglês, por sua vez, começou com a publicação de Lyricall Ballads, de William Wordsworth e Samuel Taylor Coleridge (1798). O poema Tintern Abbey é considerado pelos ecocríticos como um dos melhores exemplos românticos que representam a relação entre o ser humano e a natureza. Em Tintern Abbey, Wordsworth lembra a influência da Natureza na vida de um menino, na de um jovem e, depois, na de um homem maduro. Essa percepção é importante para a Ecocrítica, porque a natureza não é considerada pelo poeta somente como um motivo decorativo que caracteriza a composição poética, mas também um ente real e uma subjetividade capaz de moldar a natureza subjetiva do poeta.

\footnotetext{
${ }^{2}$ Veja-se Zélia Bora, em "The Amazonas Rainforest Revisited: a Critical Reading of the Novels by Dalcidio Jurandir. In : BORA, Zélia. M \& SIVARAMAKRISNAN, Murali. Narratives of Environmental Challenges in Brazil and India-Losing Nature Lexington Books. London, 2019.
}

Gláuks: Revista de Letras e Artes - jul./ dez. 2019 - Vol 19, $N^{o} 2$, ISSN 2318-7131 
Os poetas ingleses do Século XIX, ao contrário dos nossos, testemunharam rápidas mudanças no meio ambiente ocasionadas pela Revolução Industrial, que alterou, de forma brutal, as relações entre o campo e a cidade e, consequentemente, entre os seres humanos e a natureza $^{3}$. O romantismo brasileiro viveu uma espécie de conflito entre preservar e destruir a natureza, expressa de várias formas entre a primeira e a segunda gerações do movimento. Incompatível com a ideia de desenvolvimento do Século XIX, na literatura brasileira, a valorização da natureza, pelas vias do Indianismo e fora dele, provocou um descompasso entre o que se queria valorizar (a natureza e o índio) e sua negação, endossada pelas noções de progresso, diferenças culturais e, consequentemente, diferentes formas de se ver a natureza.

Por sua vez, as ideias do francês, Jean Jacques Rosseau, foram de grande importância para os românticos ingleses, no que se refere à natureza como habitat e identidade poética. Evadir-se, de fato e simbolicamente, do mundo real era uma das contingências do Romantismo. A natureza, nesse caso, era o veículo mais adequado para esses projetos. A importância da Ecocrítica como teoria e método se deve à tentativa bem-sucedida de superar o paradigma centrado na dialética história-sociedade, que reforça o antropocentrismo predatório como uma ideologia que caracteriza a relação entre o ser humano e o meio ambiente. Filosofica e cientificamente desmitificado, o Antropocentrismo, como uma ideologia, predomina causando graves efeitos às vidas humanas e às não humanas do Planeta. Como parte dos pressupostos aristotélicos, os argumentos antropocêntricos exerceram uma visão preponderante sobre a educação ocidental, que incidiu sobre a forma como tratamos a flora e a fauna do Planeta, embora, nas literaturas de língua inglesa, esse aspecto seja parte de um conjunto de saberes interdisciplinares tratados fora do cânone ecocrítico e do denominado Animal Studies (cuja essência é o estudo da Ética). A formação de uma Ecocrítica nacional pressupõe a união dessas prerrogativas, aliás, uma tendência da própria Ecocrítica anglo-saxã na presente fase, pois não se pode entender a existência dos não humanos fora de um contexto em que a flora e a fauna são interdependentes. Tanto o especismo quanto o antropocentrismo têm uma mesma raiz aristotélica e, particularmente, exerceram suas influências sobre o pensamento dos Estoicos, que se estendeu para o renascimento de Santo Agostinho e Santo Tomás de Aquino. Posteriormente, esse pensamento influenciou o pensamento de Decartes e

\footnotetext{
${ }^{3}$ The Country and the City (1973) (O Campo e a Cidade) de Raymond Williams é um livro importante, que analisa, do ponto de vista marxista, a transformação da sociedade inglesa, tomando como base as consequências da Revolução Industrial.
}

Gláuks: Revista de Letras e Artes - jul./ dez. 2019 - Vol 19, $N^{o}$ 2, ISSN 2318-7131 
de Kant (STEINER, 2005, 2). Nesse contexto, a Ecocrítica, como teoria e método, coloca-se como uma proposta que objetiva simbolicamente desmitificar esse aparato ideológico. Assinalando as premissas básicas da Ecocrítica, Hutchings assinala:

One of ecocriticism's basic premises is that literature both reflects and helps to shape human responses to the natural environment. By studying the representation of the physical world in literary texts and in the social contexts their production, ecocriticism attempts to account for attitudes and practices that have contributed to modern - day ecological problems, while at the same time investigating alternative modes of thought and behavior, including sustainable practices that would respect the perceived rights or values associated with non-human creatures and ecological processes (HUTCHINGS, 2007, p.172)

Uma das premissas básicas da ecocrítica é de que a literatura pode refletir e, ao mesmo tempo, moldar as respostas humanas ao meio ambiente. Pelo estudo da representação do mundo físico nos textos literários e nos contextos sociais de sua produção, a ecocrítica incopora atitudes e práticas que têm contribuído para discutir sobre os problemas ecológicos do dia a dia, enquanto, ao mesmo tempo, investiga alternativas e modos de pensamento, comportamento, incluindo práticas que respeitem e percebam direitos ou valores associados às criaturas não humanas e ao processo ecológico.

A relação entre a poesia e a natureza incorpora algumas considerações especiais, principalmente, no que se refere ao romantismo alemão e a sua relação com o filósofo Heidegger, cujo pensamento ecológico e a sua relação com Goethe são apontados em determinados conceitos transpostos da poesia para a Filosofia, entre eles, o de Dasein (existência do ser). A relação do filósofo com a poesia de Goethe foi considerada pela crítica ecológica como turbulenta e ambígua, sobretudo pelas críticas do filósofo ao poeta por sua

Gláuks: Revista de Letras e Artes - jul./ dez. 2019 - Vol 19, $N^{o}$ 2, ISSN 2318-7131 
posição sobre a dialética sujeito/objeto. Estudos contemporâneos como os de Ellis Dye demonstram que o conceito-chave na obra de Heiddegger, Sorge (cuidado), foi inspirado de forma incondicional no poema Fausto II Ato V. Outros personagens no poema serviram de "roteiro" para as ideias do último Heidegger sobre os perigos da tecnologia e a importância de um pensamento midiático sobre a forma como os seres humanos habitam a terra, em relação à instrumentalização do trabalho humano. Essas ideias estão contextualizadas nos ensaios de Heidegger, "Building Dwelling Thinking" e "The Question Concerning Technology" (RENDALL, 2015, p. 115).

Em sua famosa conferência intitulada 'Para que serve um poeta', sobre o aniversário da morte de Rilke, Heidegger indaga sobre o sentido do ser e seu lugar na terra. Ele escreveu essas considerações em seu refúgio na Floresta Negra ${ }^{4}$. Para ele, a experiência de habitar o mundo era concebida por meio da linguagem poética, através da qual o ser mergulha na própria natureza. Só através da poesia é que o ser pode mergulhar na própria natureza e na natureza do mundo. O mundo é a própria natureza e morada do ser. Esse pensamento é sugerido pelas seguintes palavras de Heidegger:

Dwelling occurs only when poetry comes to pass and is present... as taking a measure for all measuring. This measure-taking is itself an authentic measure-taking, no mere gauging with ready- made measuringrods for the making maps. Nor is poetry building in the sense of raising and fitting buildings. Poetry first of all admits man's dwelling into its very nature, its presencing being. Poetry is the original admission of dwelling (HEIDEGGER 1971 227).

Habitar ocorre somente quando a poesia passa e se torna presente... assumindo a medida de todas as coisas. Essa medida é em si mesma, não meramente uma medida de dimensões autofabricadas ou uma vara de sustentar mapas. Nem a poesia é feita num sentido de construir ou ajustar edifícios. A poesia, acima de tudo, permite que o ser habite em sua mais íntima natureza. A poesia é a original admissão da morada.

\footnotetext{
${ }^{4}$ Veja-se 'The Bridge and Block Forest Farm- Cultural studies blogspot.com
} 
A poesia é portanto um instrumento distante do mundo e, ao mesmo tempo, no mundo que o poeta abraça como morada, como sugere Heidegger. O poeta abraça a natureza e também estabelece sua relação com ela. Hoje, a Floresta Negra, sobre a qual o filósofo questionou a experiência do ser no mundo, é um ambiente que foi profundamente alterado depois da guerra. Poucas árvores resistem, em comparação com a exuberância da floresta que, um dia, cercou a cabana onde Heidegger morou há noventa e dois anos. Foi lá onde ele escreveu trechos definitivos do clássico Sein und Zeit (Ser e Tempo - 1927). Nesse clássico, verbos como morar e habitar adquirem sentidos poético-ontológicos, como pode ser observado nesta citação:

Only if we are capable of dwelling, only then can we build. Let us think or a while of a farmhouse in the Black Forest, which was built some two hundred years ago by the dwelling of peasants. Here the selfsufficiency of the power to let earth and heaven, divinities and mortals enter in simple oneness into things, ordered the house (HEIDEGGER, 1971 p. 160)

Somente se formos capazes de habitar, poderemos construir. Pensemos em uma cabana na Floresta Negra, que foi construída há duzentos anos pelos agricultores residentes. Aqui a autossuficiência do poder de deixar a terra e o firmamento divindades e mortais entram em uma simples unidade dentro das coisas ordenadas na morada.

Depois da Segunda Guerra e depois da escrita de, O Ser e o Tempo, Heidegger experimentou um meio ambiente completamente devastado pela guerra. Iniciada a reconstrução da Alemanha, o país passou a viver anos sob uma tensão real entre morar e habitar. A questão social da falta de moradia na Alemanha do pós-guerra e a emergência para reconstruir tanto a casa edifício quanto a "morada ontológica do ser" tornaram-se, para Heidegger, um ponto importante para suas conjecturas filosóficas sobre sua relação com o meio ambiente. Referindo-se à morada ontológica, ele não propõe somente a percepção da natureza interior, mas também da exterior, por meio da observação da natureza como subjetividade específica representada pelo poeta e pela linguagem poética. Quanto equilibrada as tensões entre morar e habitar, só então o poeta chegará a uma unidade e fusão com a

Gláuks: Revista de Letras e Artes - jul./ dez. 2019 - Vol 19, $N^{o} 2$, ISSN 2318-7131 
natureza. Aqui está implícito um paradigma específico que marca a identidade da poesia ecológica, representada também pela analogia, "sentir-se em casa". Desse modo, faz-se necessário: 1 - entender-se a natureza como morada do ser; 2. Sentir-se único e universal pelo equilíbrio entre o eu interior e o exterior (a natureza) e, finalmente, 3."sentir-se em casa" em harmonia, como mais um elemento da natureza e parte acessória da misteriosa engrenagem sob a qual se sustenta o universo. É desse modo inconteste que se estabelecem as bases filosóficas da poesia ecológica entrevistas por Heidegger.

Imerso em um universo cultural bastante distinto dos românticos "verdes" ingleses e do apelo heideggeriano, o poeta pernambucano, Joaquim Cardozo, deixa como legado curiosos sentidos para os termos morar e habitar, que, a meu ver, são fundamentais para entendermos sua poesia ecológica.

\section{Memória poética e ecologia na poesia de Joaquim Cardozo}

As leituras críticas da obra de Joaquim Cardozo, notadamente, a partir dos anos setenta, têm, normalmente, destacado a relação entre sua poesia e a representação da modernidade pernambucana. Entre esses críticos, destacam-se os estudos de Souza Barros (1972), Alfredo Bosi (1995), Neroaldo Pontes (1996), Moema D’Andrea (1998) e Elaine Cintra (2017). São unânimes as sugestões entre os críticos de que a poesia de Joaquim Cardozo é de extrema relevância para o entendimento estético dos efeitos dessa modernização sobre a sociedade em que ele viveu (1897-1978). Também foi destacado, especialmente por Moema D'Andrea e Elaine Cintra, o papel da memória do poeta de retratar os fragmentos dessa experiência (Cintra 2017). Sobre a memória social, Cintra refere:

A capital pernambucana, que passava por mal planejada modernização urbanística, vê a sua paisagem transformar-se em amplas avenidas, com prédios altos no lugar das antigas edificações. A ordem era modernizar a qualquer custo. Nesse movimento sôfrego de se adequar aos modelos europeus, bairros inteiros foram adaptados às novas necessidades da capital, 
em uma tentativa de apagamento dos traços do passado incrustados na projeção da identidade da região (CINTRA, 1996, p.188).

Da supracitada afirmação, pode-se inferir que a tensão entre a natureza e a modernização emerge de um confronto desigual entre a promessa do novo e a negação do velho. Velhas casas estavam associadas a velhos modelos culturais incompatíveis com o progresso. A natureza, por sua vez, passou a fazer parte desse debate como um componente amorfo e utilizável sob os auspícios da vontade humana. Diante dessa conjuntura, implementada na segunda metade do Século XIX, a natureza foi explorada, destruída e reconceitualizada a partir da Belle Époque brasileira (1870-1931). Extensivo a todas as capitais de norte ao sul do país, esse período conferiu, por excelência, a destruição sistemática de tudo o que representava o velho e a natureza como ente respectivamente. Desde a Região Norte, com a exploração da borracha, até as áreas urbanas como, por exemplo, a cidade do Rio de Janeiro. Esses e outros espaços tornaram-se palcos de violentas campanhas de extinção da natureza e a erradicação ou exclusão de sujeitos "avessos" ao processo de modernização 5 . Fatos como a exploração da borracha e a destruição morro do Castelo ${ }^{6}$, por exemplo, tornaram-se emblemáticos no que se refere à destruição sistemática da natureza. Nos centros urbanos, árvores e moradias centenárias foram submetidas a uma destruição inconteste, marcada, sobretudo, pela destruição de ecossistemas próximos aos centros urbanos. Como ícones da indomável força descomunal, representada por rios revoltos ou florestas de matas cerradas (como refere Euclides da Cunha em seus relatos da Amazônia), a natureza e os animais foram os primeiros entes vivos a serem sistematicamente explorados pela ideologia de expropriação colonial que, em nossos dias, estendem seus tentáculos sobre espaços globais vulneráveis e esgotados em suas capacidades ambientais. A destruição gradativa da Mata Atlântica, desde os séculos da colonização portuguesa, alterou o meio ambiente nordestino para criar os centros urbanos, como a cidade de Recife, que se tornou um desses espaços surgidos da hostilidade entre a natureza e o progresso. Enquanto no Século XIX a modernização da vida brasileira emergiu sob a figura emblemática do médico-sanitarista, como Oswaldo Cruz (1872-1917), posteriormente, despontaram imponentes, em uma segunda

\footnotetext{
${ }^{5}$ Vejam-se Nicolau Sevcenko, Literatura como Missão: Tensões Sociais e Criação Cultural na Primeira República.

${ }^{6}$ Naylor Vilas Boas: "Da abertura da Avenida Central à Derrubada do Morro do Castelo. Transformações urbanas da Belle Époque Carioca".
}

Gláuks: Revista de Letras e Artes - jul./ dez. 2019 - Vol 19, No 2, ISSN 2318-7131 
fase do Século XX, figuras como as do engenheiro, do arquiteto e do paisagista. Como artífices e, ao mesmo tempo, emissários da modernidade, a Engenharia, a Arquitetura e o Paisagismo impuseram novos estilos e formas de se conceber a natureza ou o que restou dela. Nesse cenário incongruente, surgiram o engenheiro Joaquim Cardozo (1897-1978), o arquiteto Oscar Niemeyer (1907-2012) e o paisagista Burle Marx (1909-1994). De formas diferentes, por meio de seus trabalhos, esses homens estabeleceram relações de amizade e cooperação profissional e compartilharam visões culturais comuns sobre o significado de suas profissões e seus lugares como inovadores e intérpretes da modernização. De diferentes formas, eles ( re) conceitualizaram o significado de natureza. Como testemunhas da destruição imposta pela modernidade sobre os habitats naturais, esses profissionais passaram a evocar uma espécie de ressureição estética da natureza. No caso de Oscar Niemeyer, as imagens da natureza configuram-se pela noção de curvas infinitas e pontuais, como ele definiu no "Poema da Curva", em que explica a correlação entre a natureza imaginada e seu trabalho: Não é o ângulo reto que me atrai, nem a linha reta, dura, inflexível, criada pelo homem. O que me atrai é a curva livre e sensual, a curva que encontro nas montanhas do meu país, no curso sinuoso dos seus rios, nas ondas do mar, no corpo da mulher preferida. De curvas é feito todo o universo, o universo de Einstein. (NIEMEYER, 2000)

A relação de amizade e de cooperação profissional entre Joaquim Cardozo e Oscar Niemeyer os uniu na construção de Brasília ${ }^{7}$. Como o melhor modelo de cidade imaginada e "antinatureza", Brasília incorporou o projeto de uma modernidade contraditória e artificial, não só por sua construção, já que impôs a destruição da precária vegetação do cerrado, mas também por causa da relação entre os agentes sociais e a natureza. Sob essa perspectiva, entende-se ainda mais a identidade "antinatural" da cidade, sobretudo quando se contextualiza a proposta de sua urbanização em função de um paisagismo imaginado. A (re)escritura da natureza de Brasília efetivada por Roberto Burle Marx e suas configurações espaciais são direcionadas a um sentido de preservação da natureza ou do que restou dela em forma de jardins. É conhecida a afirmação de Burle Marx quando diz: “O jardim é uma natureza organizada pelo homem e para o homem" e "onde havia peixes, há mercúrio. Onde havia

\footnotetext{
${ }^{7}$ Veja-se o artigo de Mariana Branco: Niemayer e Joaquim Cardozo: uma parceria mágica entre arquiteto e engenheiro http://www.ebc.com.br/2012/12/niemeyer-e-joaquim-cardozo-uma-parceria-magica-entre-arquitetoe-engenheiro.
}

Gláuks: Revista de Letras e Artes - jul./ dez. 2019 - Vol 19, $N^{o} 2$, ISSN 2318-7131 
florestas, há cinzas." ${ }^{\prime 8}$ Essas frases contundentes proferidas por Burle Marx protagonizam o seu testemunho sobre o antropocentrismo criminoso como uma das marcas da modernidade. Ainda como ícone da modernidade, a proposta dos belos jardins planejados por Burle Marx reproduz, de forma inconteste, a noção moderna de jardim botânico europeu com uma interpretação brasileira. Tropicais e exuberantes, os belos jardins planejados por Burle Marx metaforizam a recodificação e a ressignificação de mundo verde, uma vez selvagem e, depois, submetido à força humana predatória. Como marcas de uma visão compactada da natureza perdida, o passado selvagem da natureza e sua recriação em forma de jardim botânico e paisagismo, ainda é uma tentativa humana de domínio e de controle simbólico sobre a natureza. É também uma visão nostálgica da interrupção do curso da vida natural.

Plenamente consciente do processo de operacionalização e recriação da realidade verde efetivadas pelo paisagista, Roberto Burle Marx e o arquiteto Oscar Niemeyer, Joaquim Cardozo descreve em sua poesia a mesma fragmentação e incompletude nostálgica decorrentes de um passado irrecuperável, principalmente no que se refere à situação da natureza destruída. Como resultado, as noções de natureza fragmentada e distinta em relação aos lugares emerge nos poemas de Joaquim Cardozo, como tentaremos demonstrar.

\section{A memória ecológica de Joaquim Cardozo}

Como estamos tentando demonstrar, há uma correlação entre as ideias ecológicas de Niemeyer, Burle Marx e Joaquim Cardozo no que se refere a certa visão crítica sobre as relações entre o ser humano e a natureza. Agora estabeleceremos uma correlação entre alguns pressupostos da poesia ecológica ${ }^{9}$ e tentaremos elucidá-los brevemente em relação à poesia de Joaquim Cardozo. Entre esses pressupostos, verificaremos como o poeta se relaciona com o seu habitat; como o sentido de casa ou lar (oikos) é definido e construído em sua poesia; como

\footnotetext{
${ }^{8} \mathrm{https}$ //quemdisse.com.br/frase/o-jardim-e-uma-natureza-organizada-pelo-homem-e-para-o-homem/95294/

9 Veja-se Tom Bristow. " Ecopoetics" in Facts on file companion to the world Poetry: 1900 to Present Ed. Victoria Arana NY: Facts on file, 2008 pp.156-159.
} 
se encontram estabelecidos os sentidos simbólicos das fronteiras entre ser humano e natureza e como a memória do eu transita nesse mundo.

Em um de seus depoimentos sobre o seu trabalho como engenheiro, Joaquim Cardozo comentou:

Para mim, esse trabalho foi um verdadeiro encantamento pois vi, de perto, camaçaris de 40 metros de altura, angelins, sapucaias, deixando, de vez em quando, cair seus pixídios opérculos aberta as sementes sobre a mataria mais baixa que lhe encobriria o tronco; e de tudo as árvores a mais bela forma (...) o resto da floresta; infelizmente, nos dias de hoje, toda essa mata onde trabalhei visitando um país, uma região, uma pátria está destruída sem que se reservasse pelo menos uma parte dela, para um parque como se fez, aqui no Rio, com o alto da Boa Vista (BARROS, 1972 p.137-8).

Em suas observações, o poeta destaca dois pontos importantes: o primeiro, o sentimento de encantamento que a natureza produz sobre um ser humano sensível, e o segundo, a constatação consciente de seu lugar em relação a esse encantamento. A resposta do texto poético oscila entre esses dois polos. Para ele, a natureza é capaz de conferir ao poeta um lugar no mundo quando todas as demais possibilidades parecem esgotadas. A constatação do poeta de seu desaparecimento é real, entretanto, ele não avalia profundamente as dimensões dessa destruição (pelo menos nesta citação), que colocam em jogo a própria existência do ser humano no mundo como morada. É importante lembrar que, em meio à destruição anunciada da natureza na modernidade, emergem também a concepção de unidade pela sobrevivência e a interdependência entre as espécies, notadamente marcadas a partir das ideias de Darwin. Entretanto, o sentido de morada expresso pela linguagem poética revela que a engrenagem do mundo imaginado é a única possibilidade de redirecionar o ser humano de volta ao oikos como morada permanente do ser. Em seus poemas sobre a natureza, o poeta propõe um convite à harmonia dos sentidos, diante dos quais a natureza é vista como um traço predominante da existência prestes a desaparecer. Esses sentidos só são revitalizados pela recordação e encontram-se dispersos na poética cardoziana, enquanto as cidades de Recife, Olinda e o litoral paraibano continuam como centros dessas recordações. Nas descrições de Cardozo, não se encontra, por exemplo, a dicotomia sobrados e mocambos, tão marcada na

Gláuks: Revista de Letras e Artes - jul./ dez. 2019 - Vol 19, $N^{o} 2$, ISSN 2318-7131 
escrita de Gilberto Freyre. No entanto, predominam os espaços abertos das ruas, das pontes e de seus entornos, onde o velho e o novo convivem. Essa inter-relação entre o velho e o novo se alterna e, às vezes, sobrepõe-se aos diferentes objetos da recordação. Esse esforço mnemônico é notado, por exemplo, no poema 'Velhas Ruas' (1925). As ruas são velhas e trêmulas, sob as luzes dos lampiões do Cais de Apolo. Como uma área povoada à noite por marinheiros e prostitutas, o olhar do poeta flâneur se fixa nesses pontos mal iluminados sobre os quais "desce uma luz de pecado e remorso". A luminosidade tênue do lugar é clareada metaforicamente pela luz de vela - círio - que, como em uma oração, vela o rio morto na imaginação do poeta. Essa forte imagem sobre a precariedade da vida humana e da natureza é expressa no verso "vela de noite o cadáver do rio" (CARDOZO, p. 152). Entretanto, formaliza-se aqui um paradoxo entre a precariedade da vida humana como existência e a existência do rio cuja vida é cerceada pelas ações humanas. A vida humana e a vida da natureza entrecruzam-se.

Em outro poema do mesmo ano, chamado 'Tarde no Recife', indiferente à natureza, emerge o esplendor da criação humana - a cidade. Nesse poema, apenas um verso é dedicado à natureza. $\mathrm{O}$ rio, com sua imensidão ameaçada, parece belo a distância sob as pontes que amanhecem com o dia. Nesse poema, o rio e a cidade são objetos distintos que fazem parte de um mesmo habitat humano, como um conjunto de objetos humanos, não humanos e concretos. Porém, aos olhos do poeta, no último vero, a beleza natural da cidade não existe sem a natureza: "Recife romântico dos crepúsculos das pontes. E da beleza católica" (CARDOZO, 1925 p.154). Como um recurso poético, o rio, nesse caso, ganha atributos alheios a sua subjetividade, não obstante predomine a subjetividade humana sobre a vontade inerte do outro. Predomina, nesse caso, o papel da cultura com um viés antropocêntrico, indubitavelmente um legado ocidental da ciência iluminista, do racionalismo e da dominação do ser humano sobre a natureza. Assim, a visão do poeta não surpreende ao revelar traços indeléveis da modernidade brasileira e sua relação com a crise ecológica atual, caracterizada pela exploração demasiada das reservas naturais, pela redução das espécies animais, pela destruição e pela poluição dos componentes vitais

A recordação do poeta traz para o leitor atual as marcas de uma memória coletiva e individual. Nos poemas de 1925, a ideia de fragmentação e de solidão do eu poético é compensada por imagens sinestésicas e vibrantes da natureza como um imenso mural de cores

Gláuks: Revista de Letras e Artes - jul./ dez. 2019 - Vol 19, No 2, ISSN 2318-7131 
e apelos sensoriais que dão ao poeta um senso de pertencimento e de estar no mundo. Essas imagens se cristalizam em unidades concebidas por meio de imagens da natureza, como são os poemas 'Inverno' - “Chuva que cai, alaga o chão, encharca os ventos/ventos velas fantasmas". Essas aparições telegráficas emergem, sobretudo, nos poemas "urbanos" e aumentam nos poemas da natureza propriamente ditos, aos quais o poeta confere uma temporalidade própria da poesia, marcada por nome de meses, como setembros, outubros e dezembros, como se sugerissem os ciclos da natureza, como em "Cajueiros de Setembro". Estranhamente não foi em Recife ou em Olinda que o poeta registrou seu encontro mais marcante com a natureza, mas na praia de Tramataia (litoral paraibano da Baía da Traição). Como uma área "protegida" pela presença de remanescentes indígenas, cuja visão sobre a natureza se afasta do mecanicismo fundado pela visão decartiana, é Tramataia que ainda guarda resquícios do paraíso terrestre que foi o mundo antes da chegada humana. Esse senso de completude e de unicidade que emana desses objetos naturais "longe da civilização" está particularmente registrado no poema: 'Recordações de Tramataia' (1934).

Nesse poema, a ancestralidade da experiência humana é medida, não em termos civilizatórios, mas de legado ontológico conferido graças à relação humana com a natureza. Especificamente nesse poema, a experiência do poeta assemelha-se a um encontro quase místico que foi também traduzido em poesia por outros poetas ecológicos da tradição ocidental que habitaram a natureza, como foram os casos Wordsworth e os transcendentalistas Emerson e Thoreau. Aqui, o Eu poético incorpora a experiência do conhecimento profundamente inserido no fazer poético (poesis). Somente o exercício confere à recordação um retorno simbólico ao oikos como morada transcendental do Ser, um local de ritmos, sons e sentidos próprios, que emanam da canção da Terra ainda não violada pela ação humana. Os versos: "Eu vi nascer as luas fictícias / Que fazem surgir no espaço as curvas das marés/ Garças brancas voavam sobre os altos mangues /Da Tramataia /Bando de jandaias passavam sobre os coqueiros doidos" registram a origem e os efeitos da natureza nos sentidos como uma contemplação e introduzem um novo tipo de fenomenologia que só pode ser entendido por meio da ecopoesia. Destacam-se, aqui, os mais extraordinários perfis da natureza orgânica em perpétuo movimento singelo, em consonância com o ritmo do universo fora da vontade e da ação humana e caracterizado pelas "curvas das marés", pelas "Garças brancas", pelos "altos mangues" e pelo bando de jandaias que, juntas, garantem o dinamismo natural do mundo. Nos

Gláuks: Revista de Letras e Artes - jul./ dez. 2019 - Vol 19, $N^{o} 2$, ISSN 2318-7131 
versos "De Tramataia/E havia um desejo de gente na casa de farinha e nos mocambos vazios", suas presenças são insignificantes, porque suas ações não ameaçam a harmonia do instante situada no fluxo contínuo das águas em forma de vida. O poema traduz também a concepção de alteridade e a presença da natureza, que desafia a dimensão do ser e sua consciência em relação às entidades igualmente importantes, como os pássaros, como bases de sustentação e origem da harmonia universal.

Concluindo, o poeta assevera:

De Tramataia.

Todavia! Todavia!

Eu gostava de olhar as nuvens grandes, brancas e sólidas,

Eu tinha o encanto esportivo de nadar e dormir.

Como se pode perceber, o referido poema incorpora profundas reflexões de caráter espiritual sobre o lugar da natureza e seu papel fundante na identidade humana. Embora estejam assinaladas as marcas dessa humanidade, representadas pelas ações "nadar" e “dormir", permanecem os sentidos das primeiras impressões de encantamento e transcendentalidade que só a natureza é capaz de provocar no ser humano. Desse modo, encontra-se latente o conhecimento de que o ser humano e a natureza têm as mesmas estruturas orgânicas, que também são encontradas nas estruturas mais primitivas de vida. É nesse ponto de partida em que se fundamentam as bases ideológicas da ecopoesia, que se propõe a estabelecer uma proposta revisionista de nossa relação cósmica com a casa em que habitamos - o planeta terra. Nesse contexto, a poesia fundamenta-se como uma linguagem capaz de prover reflexões sobre a fragilidade do mundo que habitamos e de suas diversas formas, das quais somos apenas uma parcela insignificante da existência universal. 


\section{Conclusão}

A leitura da poética de Joaquim Cardozo, sob o viés ecológico/ecocrítico, formaliza-se como uma nova proposta de leitura das relações entre poesia e meio ambiente na literatura brasileira. Mediante essa perspectiva, aspectos como habitar-se (o meio ambiente) e relacionar-se com a natureza são reconhecidos por meio de um modo poético de percepção discursiva, em meio a uma série de subtemas que fazem parte da obra poética de Joaquim Cardozo, cuja poesia, em geral, destaca-se devido ao intenso apelo à fidelidade mimética. Dele, emerge a poesia da natureza como uma poderosa fonte de significado e rematerialização da linguagem. De acordo com os poemas usados como referência nesta discussão, em especial, 'Recordações de Tramataia', eles incorporam o significado do mundo natural, embora sejam necessários estudos mais profundos sobre a poesia de Joaquim Cardozo para entendermos bem mais o papel da linguagem poética na intermediação entre o humano e o não humano e se, em sua obra poética, explicam-se as questões críticas sobre o antropocentrismo.

\section{Referências bibliográficas}

BARROS, Souza. A década 20 em Pernambuco (uma interpretação). Rio de Janeiro: Gráfica Editora Acadêmica, 1972

BRANCO, Mariana. Niemayer e Joaquim Cardozo: uma parceria mágica entre arquiteto e engenheiro. Acesso disponível em 20 de julho de 2019 http://www.ebc.com.br/2012/12/niemeyer-e-joaquim-cardozo-uma-parceria-magica-entrearquiteto-e-engenheiro

BOAS, Naylor Vilas Boas. Da abertura da Avenida Central à Derrubada do Morro do Castelo.Transformações Urbanas da Belle Époque Carioca. A Belle Époque Brasileira.

Luís da Cunha Pinheiro \& Maria M. Marques Rodrigues. Lisboa: CLEPUL, 2012

BORA, Zélia \& SIVARAMAKRHISNAN, Murali. Narratives of Environmental Challenges in Brazil and India: Losing Nature. Laham: Lexington, 2018

Gláuks: Revista de Letras e Artes - jul./ dez. 2019 - Vol 19, $N^{o}$ 2, ISSN 2318-7131 
BRISTOW, Tom. Ecopoetics. Facts on file companion to the world Poetry: 1900 to Present Ed. Victoria Arana NY: Facts on file, 2008

CARDOZO, Joaquim. Poesia Completa e Prosa. Rio de Janeiro: Nova Aguilar, 2008

CINTRA, Elaine Cristina. Joaquim Cardozo e o Testemunho da década de 20. Memória e Crítica Literária no Movimento Nordestino. Miscelânia V 22, 2017

. Dos Santos, M.A \&Nascimento, R. Cidade Fatasma, Homens Autômatos: Joaquim Cardozo e o Recife dos anos 20. Percursos Literários e Linguísticos: pesquisas e processos linguísticos, literários e educativos. João Pessoa: Ed. UFPB, 2018

D'ANDREA, Moema Selma. A cidade Poética de Joaquim Cardozo. Recife: Ed. Recife, 2018

GOSMANN, Uta. Poetic Memory: The Forgotten Self in Plath, Howe, Hinsey and Gluck Laham: Lexington Books, 2012

HEIDDEGER, Martin. Poetry, Language, Thought. NY: Harperennial -Modern Classics, 2001

HUTCHINGS, Kevin. Ecocriticism in British Romantic Studies. Wiley digital Archives 4/1(2007):172-202

MARX, Roberto Burle. Quem Disse. https:/quemdisse.com.br/frase/o-jardim-e-umanatureza-organizada-pelo-homem-e-para-o-homem/95294/ Acesso disponível em 20 de julho de 2019.

NIEMEYER, Oscar. "Poema da Curva". Fundação Oscar Niemayer http://www.niemeyer.org.br/outros/poema-da-curva acesso disponível em 20 de julho de 2019

RENDAL, T. Goethe's Faust and Heiddeger's Critique of Technology. ISLE Vol 22Issue 1 pp 155-131 Winter 2015

SEVCENKO, Nicolau. Literatura como missão: tensões sociais e criação cultural na I República. SP: Brasiliense $4^{\mathrm{a}}$.ed.1995.

SLOVIC, Scott. The Third Wave of Ecocriticism: North America Reflections and the Current. Phase of the Discipline". European Journal of Literature, Culture and Environment. Ecozon@Vol/1\#1.

STEINER, Gary. Anthropocentrism and its Discontents, The moral status of animals in the history of Western Philosophy. Pittsburgh: University of Pittsburgh Press, 2005

WILLIAMS, Raymond. O Campo e a Cidade na História da Literatura. SP: Companhia das Letras, 2011.

Gláuks: Revista de Letras e Artes - jul./ dez. 2019 - Vol 19, $N^{o} 2$, ISSN 2318-7131 


\section{Abstract}

The intrinsic relationship between literature and society presupposes that literature not only represents society in its most diverse manifestations, but also proposes reflections on the social body and its relationship with its subjects. One of the contemporary issues that have influenced critical-literary production on various continents is the relationship between the subject and the environment. Although the representation of nature is not a new theme in the literature, the forms of critical questioning, through methods such as ecocriticism, emerge as an instrument that can provide the literary text with new ways of understanding the relationship between human beings and the environment. Thinking of nature in our times results in profound global implications, especially when the fate of the planet and all living things is in crisis. Thinking about Brazilian literature, taking into account tools such as ecocriticism, requires a delicate methodological exercise that can establish the textual limits and accommodate the term "ecology" suggested in the text. In this case, the notion of crisis may or may not be explicit and be more evident in some authors than in others. With this, we can only wish to achieve coherence by respecting the limits of textual composition. Thus, taking into consideration these presupositions, I propose to offer a reading of the modernist poet Joaquim Cardoso, in order to understand his view on the environment and the role of nature, especially in the poem "Memories of Tramataia".

Key Words: Ecopoetics, Ecocriticism, Memory and Identity. 